\title{
Study on application of coaching to college students' career development and employment guidance course
}

\author{
Jingqun Zhang \\ Changchun Normal University, Jilin Changchun, China 130032 \\ rose_825@163.com
}

Keywords: Education of college students; College students' employment; Entrepreneurship education; Occupation development; Employment guidance

\begin{abstract}
Coaching, as a kind of modern human resources management theory, is widely applied to modern enterprise management and has become an effective management pattern to inspire people's potential and to improve work performance. On the basis of introducing relevant theories of coaching, the paper explores the implementing ideas, operating steps, teaching design and the evaluation of the results of coaching in the college students' career development and employment guidance course, aiming to improve performance of college students' career development education and to promote the reform of college students' employment guidance course teaching.
\end{abstract}

\section{Introduction}

With the help of coaching thoughts, methods, attitude, skills and relatively perfect mental models, coaching can develop the individual's potential, achieve personal goals, team goals and organizational goals[1] . In western countries, as a new guidance and leading technology, coaching has been widely applied to the psychology, organizational behavior, education, economics, management and other disciplines. Coaching, the concept was introduced in China in 1995[2-10]. China Coaching Association was established in 2005, when it started to promote the technique across the country. However, the effect is not ideal and related theory and practices, and the researches on the development of coaching curriculum are scarce, especially the application in the field of education is insufficient. Therefore, this study tries to apply coaching to college students' career development and employment guidance course, forming coaching plan model of career development and employment guidance. Through coaching intervention activities, the study tries to promote education performance and management performance of college students' career development, and then develop suitable patterns for our country's college students' career education.

\section{Description of related theories of coaching}

The interpretation of concepts. Coaching originated in the 1970s, when American famous tennis coach Tim Gallwey proposed "concentration method" by which he taught players learn to play quickly. In the 80 s the method was applied to the enterprise management, and then the idea of Enterprise coaching came into being. To the concept of coaching, different experts and scholars put forward varied views, they think coaching is to shift staff thought and attitude through a series of communications (Perry , 2002); Coaching is to improve the process of creativity and performance 
(Sarah Thorpe, 2005); Coaching is to teach how to take actions and to achieve goals, to develop coachees' potential and to realize the creativity of results developed from the angle and aims of the customers (ACA); Tophuman International Cultural Institutions regards coaching as a method to exert the employees' potential, to improve the management technology and to achieve management objectives. Based on the above, this paper argues that coaching is to help those coachees to define their own goals, values and roles, to improve mental models, to be familiar to dealing with problems, so as to inspire potential and to improve the work performance.

The basic principle of implementation of coaching. The concept of humanity assumption of coaching sees everyone as a productive individual. The coach's role is to understand the coachees' internal demand, to help them know the current status, in order to achieve the target set. Therefore, from the mentality of employees, with the aid of various management means such as trust, guidance, motivation, coaching helps employees to improve action, and finally to achieve the desired results. Compared with traditional management methods, coaching emphasized the needs of employees rather than the perfection of rules and production process. Coaching views the staff as the main body of creative resources, tries to exert human resources, and puts these resources into productivity. In mental models and results change model, as in the individual philosophy, people take mental change (value orientation, value evaluation) as the starting point and the basis of behavior change, finally realize the change of the results. The management and leadership which mastered the core ideas is to be more efficient. In addition, the core of the formula of coaching: Performance= potential interference, namely: $\mathrm{P}=\mathrm{P}-\mathrm{I}$. We can see that from the formula the most ideal state of coachees is zero outside interference, which means performance is equivalent to potential. In other words, interference can affect the person's action in reality, or prevent individuals from developing potential.

The basic abilities of coach. The widespread application and practice of coaching is mainly accomplished by the coach, so the coach's abilities are directly related to the effect of the technique. In the process, the coach needs to possess basic skills of listening, asking questions, distinguishing and responding. Among them, listening means to understand the coachee's mind on neutral stands; asking questions is to understand the coach's status, find the existing problems, remove their confusion and doubt, to find out the specific measures to solve the problem, and to inspire and help look for the answer; distinguishing requires the coaches is to clarify the truth, understand the goals and expectations, the logical ties between facts and assumptions, help coachees find their blind spots and form the correct model and professional beliefs; responding means that through summarizing experience, giving feedback of coaching, coachees can realize their own strengths and weaknesses, and further adjust the future implementation of the goal, to establish confidence, and to put forward a new challenge. In the process of implementation of coaching, the four skills need to be used expertly, which can improve the cognitive level of those coaches. Otherwise, it will cause coachees' resistance resulting they are unable to achieve the goals.

The implementing steps of coaching. First, the implementation of coaching requires determining the goals. Goals are the expectation of a person, department and organization. The goals are also the state the coach and coachee try to achieve through the common efforts. In practical operation, first, goal setting should based on the inner demands of coachee, and everyone participates in setting their own goals, and to stimulate their initiative and creativity. Second, the implementation should reflect truth. In this process, the role of coach is to reflect the truth and help coachee understand their own behavior and attitude, action and slogan, and the gap between representation and the fact. In the process coachees can get rid of a subjective and one-sided view, deduce 
conclusion from "facts", and establish the communication with sincerity, equality, trust. Third, the improvement of mentality. The core of leadership of coaching is to change the coachees' points of view. The correcting of minds result in positive initiative, which will produce new possibilities. Fourth, implementation of action plan. After the above activities, coaching is to encourage and inspire them to overcome difficulties with rigorous selection, which is also the expression of the coachee's own will. The action plan must be practical and feasible. If the plan is too simple, it will make coachee lose interest. The four stages of implementing coaching: goal setting $\rightarrow$ reflecting the objective truth $\rightarrow$ improvement of mentality $\rightarrow$ implementing action plan. The stages are closely linked together. Only object goals can reflect truth and improve mentality. Only to implement action plan can realize the real significance of goals and can reflect value of coaching.

\section{The concept of applying coaching to college students' career development and employment guidance course}

Based on the relevant theories of coaching, its basic concept of applying it to the college students' career development and employment guidance course includes the following parts: first, take the student as the standard, arouse the students' motivation and self development potential, to improve students' self learning, the basic ability of solving problems. It helps students to explore the basic method to solve problems, which is the important principles of the college students' career planning and employment guidance curriculum. In college students' employment guidance course, the teacher is no longer to impart the traditional knowledge, but to inspire students' career awareness, explore all kinds of problems in the process of professional development, to set up career planning consciousness and make reasonable career plan. Second, in the process of implementation of coaching, we take it as a kind of open, social, and practical education. College students' career development education need to take advantage of all kinds of education resources, including: government, employer and school resources. The course should integrate and optimize all kinds of resources and take them into college students' employment guidance course teaching.Third, the sinicization and localization of coaching in the college students' career development and employment guidance course. This requires combining our country's higher education system with practical situation of schools and students, to set a reasonable career development goals, to improve students' professional skills and professional quality, to form the correct values of employment, and to reveal the vitality and effectiveness of employment guidance course.

\section{Coaching in the college students' career development and employment guidance course teaching operation}

In order to further verify the effect of coaching in the college students' career development and employment guidance course teaching. This study chose Changchun Normal University Employment Guidance Teaching and Research section as the experiment center. The study based on colleges and established coach special working group, unified employment guidance curriculum planning and project implementation process. The coaching included the following stages: the first stage, to made a plan for college students' career development and employment guidance curriculum design, experiment plan, which including: the experimental time , teaching mode, curriculum organization; The second stage, select teaching coach staff of college students' career development and employment guidance course. And for the selection of personnel on the basis of professional 
characteristics, industry distribution, and the characteristics of the professional type division of labor, training; Third stage, with the aid of the university networking platform to promote the implementation of the coaching, organized the student to the networking application, chose the coach, and filtered according to the application situation and the team; The fourth stage, the coach technical activities of the organization implementation and process control. Activity time and place are decided by coaches, the frequency of the activities employment guidance course teaching is once a week, collective activity organized each month. The project supervised over the quality of activities, and maintained frequent communication and exchanges; The fifth stage, to share and evaluate results of the coaching in the college students' career development and employment guidance course teaching. Every time after the teaching activities and group activities, coaching team members need to write summary report, explicit about the problems existing in the learning process and their shortcomings. Carry out relevant research and evaluation work actively, and show the learning outcomes to each team coaching activities, and discuss the common problems in workshops.

\section{Coaching in the college students' career development and employment guidance course design}

The content of the college students' employment guidance course instructor module design mainly involves four aspects of the subject, i.e., the university students' employment skills module, professional quality upgrade module, professional environment to explore module and self-knowledge module, the resulting module framework of college students' employment guidance course teaching; Coach of the college students' career development pattern design, strengthening the career education into the coaching project activities, including training, team development and forms to carry out three coaching, and hired well-known coach staff on centralized lecture teaching, the goal of education focuses on training students' professional quality; College students' employment guidance course teaching content design, let students understand and correct understanding of modern employment situation, takes the vocational values education, sets up the lofty ideal and ambition.

\section{The application and evaluation of coaching in college students' career development and employment guidance course}

After one year's College students' career development and employment guidance course, in the coaching course mode, coaching theory, has accumulated rich experience. The participation coaching training involved 96 college students, from the point of the teaching effect the results of a survey, 93.8\% students satisfied or very satisfied, $85.4 \%$ students learned by coaching deepened the understanding of the future career development, $77.1 \%$ students thought that their own communication ability has been significantly improved, 56.3\% students thought their interpersonal relations have improved significantly, $78.1 \%$ students agreed that personal career planning and job skills have been greatly improved. In addition, the student gave a high evaluation to the employment guidance course content practicability, breadth and depth.Coaching in the teaching of college students' career development and employment guidance course intervention effect, with the help of career self-efficacy scale and career decision-making difficulties questionnaire were tested [5], among them, self-efficacy, coaching before the test results of average of 167.4, test results after the intervention was 188.2, before and after the intervention of independent sample T-test results show very significant difference $(\mathrm{P}=0.002)$. Career decision-making difficulties test results scored an 
average of 93.4 before intervention, intervention after the test results of 73.5 , before and after the intervention of independent sample $\mathrm{T}$-test results show very significant difference $(\mathrm{P}=0.000)$. Intervention effect of the statistical results show that the coaching for college students' career planning and development of confidence, career orientation, professional quality and professional ability, etc have a greater degree of improvement.

\section{The conclusion}

Coaching in the college students' career development and employment guidance course have obvious positive transfer effect, for the college students' career decision-making and development, professional mental health education, comprehensive quality has obvious promoting role. At the same time, the implementation of the coaching has changed traditional concept of employment guidance course teaching, and arouse the students' self learning, self development, positive initiative, students are one of the biggest potential have important meaning. However, coach technology in the college students' career development education implementation is only a tentative exploration of this study, for the continued development, coach model of structural design still need to be further in-depth study.

\section{References}

[1] G.. Chen: Commercial Economics Review,2005,19 (3) :76-78.

[2]Liu Miaoling: Master thesis,Jinan University,2004.

[3]Jerry.w.looks, Tower, W.Bouton, Wan Pinyan translation..Beijing:Mechanical industry press,2004. [4]H. Wei, W.Bo, C. Zhen: Education and Vocation,2009,21(9):83-85.

[5]W.Yan. ShanghaiNormal University, master's degree thesis,2008.

[6] Jessica Jarvis: Chartered Institute of Personnel and Development. 2004,Vol(6): 19-26

[7]W. Strunk Jr., E.B. White: The Elements of Style, third ed., Macmillan, New York, 1979.

[8]G.R. Mettam, L.B. Adams: How to prepare an electronic version of your article, in: B.S. Jones, R.Z. Smith (Eds.), Introduction to the Electronic Age, E-Publishing Inc., New York, 1999, pp. 281-304.

[9]R.J. Ong, J.T. Dawley and P.G. Clem: submitted to Journal of Materials Research (2003)

[10]P.G. Clem, M. Rodriguez, J.A. Voigt and C.S. Ashley, U.S. Patent 6,231,666. (2001) 